\title{
Cristo y la Iglesia en la encrucijada de la inculturación
}

\author{
Mario Alberto Molina, O.A.R., \\ Universidad Rafael Landívar, \\ Guatemala.
}

La inculturación es un desaflo y un criterio de evangelización; aś́ titulé una intervención en la semana de pastoral, celebrada por la Orden de Agustinos Recoletos, en Santo Domingo, en mayo de 1992(1). Si algo ha ocurrido desde esa fecha hasta hoy es que el reto de la inculturación se ha agudizado como desafío pastoral; y el criterio de la inculturación como parámetro de la evangelización exitosamente realizada se ha confirmado en los pronunciamientos del magisterio y los escritos de los té́logos(2). En este articulo deseo profundizar en la naturaleza teológica y en las implicaciones pastorales de la inculturación. Porque, aunque el término es nuevo, el propósito que expresa ha estado presente con mayor o menor evidencia en la conciencia eclesial a lo largo de los siglos y constituye una dimensión inadmisible de la tarea evangelizadora de la Iglesia católica por la naturaleza de la revelación cristiana.

1. Mario A. Molina, "Inculturación: desaflo y criterio de la evangelización", Recollectio 16 (1993), pp. 23-57.

2. El documento pontificio que trajo a la conciencia de la Iglesia el tema de la inculturación fue la exhortación apostólica Evangelii nuntiandi ( 8 de diciembre de 1975) de Pablo Vl. Luego, Juan Pablo II ha tratado el tema de la inculturación en diversos documentos. Muy importantes son las cartas encíclicas Redemptoris missio (7 de diciembre de 1990) y Slavorum apostoli (2 de junio de 1985), juntamente con la exhortación apostólica Carechesi tradendae (16 de octubre de 1979). Por lo que se refiere a la bibliografla sobre el tema, el libro de P. Aguirrebalzategi, Configuración eclesial de las culturas: hacia una teología de la cultura en la perspectiva del Concilio Vaticano II (Teología Deusto, 8; Mensajero, Bilbao 1976), resulta, al leerlo veinte años después de que fuera escrito, clarividente y profético en sus planteamientos; es una magnifica sistematización de la temática. F. Miguens Dedyn hace una presentación sistemática del pensamiento de Juan Pablo Il sobre el tema en Fe y cultura en la enseñanza de Juan Pablo II, (Madrid 1994). La bibliograffa sobre el tema de la 


\section{Fundamentos teo-lógicos de la inculturación}

La necesidad de tener en cuenta la dimensión cultural del proceso evangelizador está fundamentada en la naturaleza de la revelación. La revelación de Dios se realiza por la creación y los acontecimientos históricos, principalmente por la vida, la muerte y la resurrección de Jesucristo. Esta es doctrina calólica, como lo afirma el propio Vaticano I:

La misma santa Madre Iglesia sostiene y enseña que Dios, principio y fin de todas las cosas, puede ser conocido con certeza por la luz natural de la razón humana, partiendo de las cosas creadas; porque lo invisible de $\mathrm{El}$, se ve, partiendo de la creación del mundo, entendido por medio de lo que ha sido hecho (Rom 1, 20); sin embargo, plugo a su sabiduría y bondad revelar al género humano por otro camino, y éste sobrenatural, a sí mismo y los decretos eternos de su voluntad, como quiera que dice el Apóstol: Habiendo Dios hablado antaño en muchas ocasiones y de muchos modos a nuestros padres por los profelas, últimamente, en estos mismos días, nos ha hablado a nosotros por su Hijo (Heb 1, 1-2) (D 1785).

Ciertamente, el Vaticano I habla del conocimiento que el hombre puede tener de Dios a través de la creación; pero la afirmación de la posibilidad de ese conocimiento se basa en el hecho de la revelación de Dios por ese medio. Al hablar de la revelación histórica, la señala como "otro camino" de revelación, en referencia a la creación, que sería el primer camino de revelación de Dios. El otro, el segundo, está descrito con la cita de Hebreos 1, 1, que recoge, en una magnífica síntesis, la historia de la revelación de Dios a Israel como un proceso fragmentario, incompleto y diverso, que concluye con la unicidad, la integridad y la singularidad de la revelación en Jesucristo. El concilio llama a esta segunda vía sobrenatural, implicando que la primera es natural.

inculturación podŕa llenar páginas, sobre todo si se tienen en cuenta los artículos diseminados por todo tipo de revistas. Menciono algunas obras que merecen consideración. Para un planteamiento introductorio del tema desde la perspectiva latinoamericana se debe consultar el artículo de P. Suess, "Inculturación" en Mysterium liberationis: concepros fundamentales de la teologia de la liberación (I. Ellacuria-J. Sobrino ed. UCA Editores. San Salvador 1992; Tomo II, 377-422). Para una tome de conciencia de los retos de la cultura occidental a la evangelización en Europa y en España en particular remito al libro de J. Martín Velasco, El malestar religioso de nuestra culiura, (Paulinas, Madrid 1993). Para el tema de la cultura occidental y urbane como reto a la evangelización en América Latina, M. de C. Azevedo presenta una buena introducción en Vivir la fe en un mundo plural: discrepancias y convergencias (Verbo Divino, Estella 1993). Para una reflexión sobre el desafío que las culturas autóctonas de América presentan a la evangelización remito al libro coordinado por J. Espeja, Inculturación y reología indígena (Editorial San Esteban, Salamanca 1993); y al libro coordinado por D. Salado, Inculturacion y nueva evangelización (Editorial San Esteban, Salamanca 1991). 
La contraposición "natural" y "sobrenatural" no tiene que ver con la identidad del Dios revelado, como si uno [uera el Dios que se revela en los acontecimientos históricos (el Dios cristiano, digamos) y otro el que lo hace en la obra de la creación (el "Dios de los filósofos"). Ni tiene que ver con la gratuidad de la revelación de Dios, como si la manifestación de Dios a través de la creación fuera inherente a la obra ("natural") y la manifestación a través de la historia fuera discrecional o, peor aún, sobreañadida. Por su señorío, Dios está presente en la creación entera y guía toda la historia humana de modo que toda ella, como toda la creación, es revelatoria. Hace falta siempre, sin embargo, la voz de los profetas y hagiógrafos que verbalicen ambas formas de la revelación; y esta experiencia es la que tuvo Israel en vistas a la plenitud de la revelación en Cristo. La contraposición entre la revelación natural y la sobrenatural tiene que ver con los medios por los que se realiza: por la creación o naluraleza, y por la historia, a través de los actos de la libertad humana.

El Concilio Vaticano II, que no está tan preocupado como el Vaticano I por la posibilidad de conocer a Dios, cuanto por la declaración de la efectiva voluntad de Dios de darse a conocer, cita los mismos textos bíblicos, leyéndolos desde la perspectiva de la voluntad de Dios de manifestarse a los hombres:

Dios, creando y conservando el universo por su Palabra (cfr. Jn I, 3), ofrece a los hombres en la creación un testimonio perenne de Sí mismo (cfr. Rom 1, 1920); queriendo además abrir el camino de la salvación sobrenatural, se reveló desde el principio a nuestros primeros padres. [...] Dios hablo a nuestros padres en distintas ocasiones y de muchas maneras por los profetas. Ahora, en esta etapa final nos ha hablado por el Hijo (Heb l, 1-2). Pues envio a su Hijo, la Palabra etema, que alumbra a todo hombre, para que habitara entre los hombres y les contara la intimidad de Dios (cfr. Jn 1, I-18) (Dei Verbum, 3.4).

La conciencia de que el acceso a Dios y la posibilidad de entablar una relación con El se fundan en un movimiento de aproximación original y primario que parte de El, lo que en teología cristiana llamamos revelación. Esta es la base para todo esfuerzo de inculturación, porque la captación de la dimensión divina en la creación y de la presencia de Dios en los acontecimientos históricos de un pueblo son experiencias condicionadas, vividas y expresadas desde una cultura concreta, la de ese pueblo cuya historia y experiencias son vehículo de la revelación de Dios. Por otra parte, si la creación es testimonio que Dios da de sí, este testimonio es accesible a cualquier ser humano, en cualquier parte del mundo y cultura; además, toda religión que tome pie en la percepción de lo divino en la creación es ya respuesta y captación -no importa cuán rudimentaria y diferente de la cristiana- de la revelación de Dios. Esto implica que la revelación de Dios en la creación y en la experiencia histórica es fundamento teológico de la respuesta 
religiosa del hombre en todas las épocas(3).

En efecto, la creación siendo una y la misma, no significa lo mismo para las diversas culturas. Por lo tanto, la revelación de Dios en la creación ofrece diversas imágenes de la divinidad, imágenes que están culturalmente expresadas y condicionadas. Las culturas agrícolas, cuyo contacto con la naturaleza es inmediato y vital, perciben a través de la naturaleza una divinidad con rasgos que acentúan los aspectos de fecundidad y de vida. La forma actual de la cultura occidental, en donde la relación con la naturaleza y con la creación, está medializada por la técnica y es con frecuencia una relación de explotación, se ha hecho más insensible para percibir la revelación de Dios por la creación. Puede ocurrir que la cultura occidental con su tecnología y vida urbana de tal forma se interponga entre la naturaleza cosmológica y el hombre que solamente algunos espacios de la creación estén abiertos a la transcendencia, quizá los espacios de la naturaleza personal, en forma de la experiencia de la propia interioridad. La relación con la creación está, pues, culturalmente mediatizada y por eso la percepción de la divinidad está culturalmente diversificada.

El Dios único se revela en la misma creación, pero no muestra por eso la misma cara. La cara de Dios que se dibuja en la creación está mediatizada por la cultura y se concreta en las concepciones de la divinidad presente en las diversas religiones del mundo. $Y$ si bien de todas las religiones se puede decir que captan y expresan la revelación de Dios en la creación, los creyentes en Cristo juzgan con respeto- la adecuación de esa representación de Dios, de acuerdo con la propia experiencia de Dios. Si Pablo, según san Lucas, podía hablar con estima y valorar como positivo el altar al Dios desconocido que encontró en Atenas (Hech 17, 23), en la carta a los Romanos descalifica como inadecuado el conocimiento de Dios a partir de la creación, la representación de la divinidad por medio de imágenes animales, astrales e incluso antropomórficas. Cuando Pablo fustiga a los paganos en el texto de Romanos, citado por los concilios, no dice

3. "Aqú entendemos la revelación no como comunicación de un contenido aislado determinado, sino como modificación de la situación última del horizonte trascendental del hombre. En este caso existe un cambio gracioso y libre de la conciencia humana obrado por Dios, y esto ya es algo que aunque no exclusivamente también puede llamarse revelación. [...] En este supuesto podemos decir que con la historia general sobrenatural de la salvación se da ya necesariamente una historia general sobrenatural de la revelación y de la fe, que, una vez más, tiene la misma extensión que la historia general del mundo. Lo que se suele llamar historia de la revelación (desde Abrahán a Moisés, o también lo que se entiende en su tradición como revelación primitiva de proposiciones) aparece como historia particular de la revelación y la salvación". A. Darlap, "Teologfa fundamental de la historia de la salvación", en Mysterium salutis: manual de teología como historia de la salvación (J. Feiner, M. Lohrer, ed.) Cristiandad, Madrid 1969, I/1, p. 130. 
que no conocieron a Dios, sino que, habiéndolo conocido, no lo representaron ni se lo imaginaron de manera digna, de modo que quedaron atrapados en las formas creaturales en las que lo percibieron (Rom 1, 19-23). Por otra parte, en un oráculo audaz y de interpretación discutida, Malaquías censura el sacrificio que se ofrece a Dios en Jerusalén e indica que a Dios no le falta por eso culto, pues se complace más bien en el que se le ofrece en las naciones: "No me complazco en ustedes, dice el Señor todopoderoso, ni me agradan las ofrendas que me presentan. Porque desde donde sale el sol hasta donde se pone es glorificado mi nombre entre las naciones, y en todo lugar se ofrece en mi honor un sacrificio de incienso y una ofrenda pura. Mi nombre es honrado entre las naciones" (1, 10-11).

También el Concilio Vaticano II recoge una conciencia que se va fraguando desde los mismos inicios de la evangelización:

Ni el mismo Dios está lejos de otros que buscan en sombras e imágenes al Dios desconocido, puesto que todos reciben de El la vida, la inspiración y todas las cosas (cfr. Hech 17, 25-28) y el Salvador quiere que todos los hombres se salven ( $c f r$. ITim 2, 4). Pues quienes, ignorando sin culpa el Evangelio de Cristo y su Iglesia, buscan, no obstante, a Dios con un corazón sincero y se esfuerzan, bajo el influjo de la gracia, en cumplir con obras su voluntad, conocida mediante el juicio de la conciencia, pueden conseguir la salvación eterna. Y la divina Providencia tampoco niega los auxilios necesarios para la salvación a quienes sin culpa no han llegado todavía a un conocimiento expreso de Dios y se esfuerzan en llevar una vida recta, no sin la gracia de Dios. Cuanto hay de bueno y verdadero entre ellos, la Iglesia lo juzga como una preparación del Evangelio y otorgado por quien ilumina a todos los hombres para que al fin tengan la vida. Pero con mucha frecuencia los hombres, engañados por el Maligno, se envilecieron con sus fantasías y trocaron la verdad de Dios en mentira, sirviendo a la criatura más bien que al Creador (cfr. Rom 1, 21.25) (Lumen Gentium, 16).

Esta conciencia de la revelación a través de la creación crea necesariamente una actitud evangelizadora peculiar. Las formas religiosas que existen al margen de la revelación judeo-crístiana o las que se desarrollan al margen de la institución eclesial en las naciones de algún modo evangelizadas son posibilidades de captación de la revelación de Dios en la creación, a veces en dimensiones inéditas o en aspectos soslayados en la revelación cristiana, pero no por eso menos válidos.

Veamos ahora qué podemos decir en tomo a la revelación de Dios en la historia. La Escritura afima que los pueblos del mundo están bajo el gobiemo de Dios en el desarrollo y curso de su propia historia. No dice tan claramente, sin embargo, si Dios, al guiarlos en el curso de su historia, se deja igualmente conocer en los acontecimientos históricos. En Listra, con estas palabra presenta 
Pablo el mensaje de salvación: "En las generaciones pasadas, él permitió que cada pueblo siguiera su propio camino; aunque no dejó de darse a conocer por sus beneficios, enviándoles desde el cielo lluvias y temporadas fructíferas, y Ilenando de alimento y alegtía sus corazones" (Hech 14, 16-17). De un modo mucho más optimista habla Pablo en Atenas: "Dios creó de un solo hombre toda la humanidad para que habitara en toda la tierra, fijando a cada pueblo dónde y cuándo tenían que habitar, con el fin de que buscaran a Dios, a ver si, aunque sea a tientas, lo podían encontrar; y es que en realidad no está lejos de cada uno uno de nosotros (Hech 17, 26-27). "Seguir el propio camino, lijar a cada pueblo dónde y cuándo tienen que habitar" son expresiones que hablan del señorío histórico de Dios entre los gentiles. Y en un magnífico oráculo recriminatorio a Israel, que se cree el único pueblo de la tierra protegido por Dios, declara Amós: "¿No son ustedes para mí como etíopes, hijos de Israel? Oráculo del Señor. ¿No saqué yo a Israel de Egipto, a los filisteos de Creta y a los sirios de Quir?" (Am 9,7). Es decir, la palabra profética, que descubre la presencia salvadora de Dios en las gestas históricas de Israel, la intuye también en los acontecimientos por los que otros pueblos alcanzan su liberación y configuración política; es posible, por tanto, afirmar que a la luz de la revelación histórica a Israel, los otros pueblos de la lierra pueden llegar a descubrir, como por analogía, en su propia historia, el señorío salvador de Dios, como lo hizo Israel, gracias a la mediación de la palabra profética. El gobiemo y la soberanía de Dios en la conducción de la historia de los pueblos del mundo a una mayor dignidad, libertad y plenitud es una afirmación de la fe judeo-cristiana. Que ese itinerario haya sido vehículo de la revelación de Dios mediante la palabra profética que explicitaba la dimensión divina de los acontecimientos es algo que, sin duda, podemos afirmar solo de Israel y la revelación cristiana.

Con lo que llevamos dicho, podemos afimar, desde la fe cristiana, que la revelación de Dios como oferta de salvación es una gracia universal: Dios se ha dado a conocer a través de la creación y la historia a todos los pueblos, aunque la claridad de esa percepción se haya verbalizado sólo en Israel en vistas a la revelación en Cristo.

Debemos considerar ahora otro aspecto del problema. Esa revelación a Israel está mediatizada por la cultura concreta de Israel. La revelación especial de Dios se ha dado en una historia concreta. Israel conoció a Yahvé en los acontecimientos de la liberación de Egipto, cuya raíz remota fue la promesa a los patriarcas y cuyas consecuencias posteriores fueron la conquista de la tierra, el establecimiento de la monarquía, la consolidación del culto en el templo y la aparición del ministerio profético. La crisis del exilio y la pérdida de la libertad abrieron el horizonte a la esperanza mesiánica de salvación definitiva en un futuro determinado por Dios. La plenitud de esta historia de revelación la constituye la manifestación de Jesucristo como realización de las esperanzas de salvación y libertad. 
La revelación de Dios no consiste primariamente en la manifestación de ideas o doctrinas, sino en la experiencia de Dios, por medio de un encuentro con él en acontecimientos que se experimentan como salvificos y, por eso mismo, transparentes de Dios(4). Pero la característica de los acontecimientos históricos, sea que afecten a una sola persona o a todo un pueblo, es su singularidad irrepetible. Ocurren en un pueblo concreto y son interpretados y recordados en una lengua concreta; son comprendidos desde los conceptos propios de una cultura; son celebrados en los ritos y símbolos disponibles en esa cultura. Es decir, la revelación histórica de Dios a Israel y en Jesucristo, al ser históricas, están interpretadas y expresadas por la cultura de Israel.

Además, esta cultura, como toda cultura, no es estática, sino dinámica y cambiante. Los mismos libros de la Escritura dan testimonio de ello: están escritos en tres lenguas diversas, y sabemos de qué manera la lengua es el rostro de la cultura. El relato de la Escritura refleja cambios culturales: entre la cultura seminómada de la época patriarcal a la cultura sedentaria y estatal de la época monárquica hay un abismo. Desde la cultura semita condicionada por los influjos asirios, babilónicos, cananeos y egipcios, a la cultura postexflica, abierta a los influjos persas primero y griegos después, hay toda una evolución cultural que introduce conceptos, desplaza acentos, reforma sistemas de comprensión que entran en juego en la apropiación que Israel y la Iglesia apostólica hacen, mediante la lengua y los ritos, de la revelación de Dios en la experiencia histórica.

De ahí que el desafío y el reto de la inculturación no sean una moda advenediza y pasajera, sino una obligación y responsabilidad evangelizadora, que surge de la misma naturaleza de la revelación de Dios. La revelación de Dios, tanto la que se realiza por la creación como la que tiene lugar por acontecimientos históricos, ha sido caplada y expresada a través del desartollo cultural de Israel. La revelación de Dios está mediatizada culturalmente. El análisis somero que acabamos de hacer es que la misma revelación de Dios por la creación está históricamente y culturalmente condicionada, por cuanto la comprensión de la creación y la percepción de la divinidad a través de ella están mediatizadas por la cultura. Y, de la misma manera, la revelación de Dios en acontecimientos

4. "De lo dicho se desprende, pues, con claridad el significado fundamental de la revelación como fundamento: esa receptividad radical, en la que el hombre, acogiendo la presencia salvadora de Dios, va entrando en su plena realización. [...] Con lo anterior queda expresado lo fundamental de la revelación: esa historia englobante en la cual el hombre se va descubriendo y realizando en su intimidad, en cuanto determinado y entregado a sí mismo por el Dios que se le comunica." A. Torres Queiruga, $L$ revelación de Dios en la realización del hombre (Cristiandad, Madrid 1987, p. 203). La cursiva es del autor. Entiendo que la palabra "intimidad" no significa en esta cita privacidad, como si la revelacion y su experiencia fuera algo individual y secreto, sino que significa desde el censro del ser y de la existencia humana. 
históricos está mediatizada por ellos que son cultura y están sujetos a una interpretación cultural.

Ahora bien, la revelación de Dios se distingue netamente, aunque no se pueda separar, de la cultura en la que se expresó originalmente. "El Evangelio y, por consiguiente, la evangelización -decía Pablo VI-no se identifican ciertamente con la cultura y son independientes con respecto de todas las culturas" (Evangelii nuntiandi, 20). Por lo tanto, la revelación de Dios en la creación y en la historia, aunque ha sido aprehendida en Israel y transmitida en la Escritura por la mediación de formas culturales concretas, es susceptible de ser comunicada a hombres y mujeres de otras culturas. Como lo definitivo no es la mediación cultural en la que se captó la revelación, sino la experiencia salvífica de Dios, conocida a través de la mediación cultural, la tarea de la comunicación de la experiencia salvífica y de la revelación de Dios, si, por una parte, no puede prescindir de la mediación cultural original en que se formuló, por otra parte, no puede poner el acento en ella ni considerar que la revelación de Dios no se distingue de la mediación cultural en que se expresa.

Por una parte, el mensaje evangélico no se puede pura y simplemente aislar de la cultura en la que está inserto desde el principio (el mundo bíblico $\mathrm{y}$, más concretamente, el medio cultural en el que vivó Jesús de Nazaret); ni tampoco, sin graves pérdidas, podrá ser aislado de las culturas en las que ya se ha expresado a lo largo de los siglos; dicho mensaje no surge de manera espontánea en ningún "humus" cultural; se transmite siempre a través de un diálogo apostólico que está inevitablemente inserto en un cierto diálogo de culturas (Juan Pablo II, Catechesi tradendae, 53).

Porque la evangelización está "inevitablemente inserta en un cierto diálogo de culturas" es necesario tomar en cuenta el factor cultural en todo proyecto de evangelización, no sólo para que la revelación sea aceptada, sino para que sea nuevamente expresada.

\section{El problema cristológico}

El problema cristológico queda planteado por la afirmación cristiana de que la salvación viene de los judios (Jn 4, 22), lo cual es un escándalo. En efecto, la predicación de la fe no consiste primariamente en la transmisión de ideas y doctrinas, sino en la presentación de la experiencia histórica de Dios, realizada por Jesús de Nazaret, como una posibilidad de transcendencia y plenitud accesible a todo hombre. Pero por ser una experiencia histórica, la vida y la obra de Jesús están condicionadas por su cultura, las coordenadas geográficas y temporales que lo sitúan en un país concreto y en una época determinada. De modo que el anuncio del evangelio tiene un aspecto inmediato y evidente de ser algo foráneo, extranjero. 
Para facilitar la comprensión de lo que quiero decir, pongamos un ejemplo radical y válido, aunque quizá sólo en los pueblos de Asia. En la evangelización de naciones que no conocen el cristianismo, el evangelizador se encontrará con formas religiosas que derivan en mayor o menor medida de la revelación de Dios en la naturaleza. Encontrará formas religiosas y religiones por las que se da respuesta a interrogantes en torno a realidades humanas como la vida, la muerte, el sufrimiento, el mal, el pecado, la responsabilidad ética y la aspiración a la plenitud; por las que se responde a la gratuidad de la fecundidad de la tierra o de los mares; por las que se intenta responder a los cuestionamientos acerca del origen del mundo y la humanidad y su destino. En el trato que'esas religiones dan a estos problemas, el evangelizador cristiano puede encontrar creencias e ideas contrarias y discrepantes de las propias, pero también valoraciones o concepciones coincidentes, o por lo menos convergentes, con sus propias convicciones y creencias cristianas. Muchas veces no las reconocerá a primera vista, pero el trato asiduo le permitirá descubrir múltiples valores evangélicos.

Siguiendo con el ejemplo imaginario, ese evangelizador occidental, desengañado con la degeneración de su propia cultura y avergonzado de los excesos cometidos por los cristianos europeos en la tarea de evangelización de Africa y América, quiere ser cauto para no cometer los mismos errores ahora que se encuentra en una población que desconoce el cristianismo y los vicios de la cultura occidental; el evangelizador quiere conservar la cultura que ha encontrado en su prístina pureza. Ese evangelizador será sumamente sensible a los valores religiosos de la cultura que ha encontrado; la propia fe lo ayudará a descubrir los elementos "cristianos" que existen en esa cultura, incluso vividos de manera más sincera, auténtica y profunda que en el país, supuestamente cristiano, de donde viene. Pero llega un momento en que, si quiere ser fiel a su misión y a su fe, liene que hablar de una persona extraña, desconocida, procedente de otra cultura. Tiene que pronunciar el nombre de Jesús de Nazaret y decir que ése, que hasta ahora no conocían, es el salvador del mundo. Y como Jesucristo es un ser humano, liene que contar su historia; y entonces entran en el discurso fariseos y publicanos, romanos y herodianos. $Y$ como Jesús de Nazaret no surgió de la nada, tiene que hablar de Israel, de Abrahán, de Moisés, de David, de Isaías y de Amós. Tiene que contar una historia que, de momento y al parecer, no tiene nada que ver con la vida, la historia y las preocupaciones del pueblo al que ha Ilegado a evangelizar. Sabe que con ese discurso va a alterar irremediablemente la cultura que intentaba conservar.

El problema es imaginario en su planteamiento, pero no es ficticio. He aquí las preguntas que se hacía un evangelizador de poblaciones mayas de Guatemala hace unos años(5):

5. C. Berganza, "Teología india", en J. Espeja, Inculruración y teología indígena (Salamanca 1993), p. 135. 
Aparte de todos estos problemas de comunicación está el gran reto de Cristo. el problema cristológico. Al hablar de Dios hay menos dificultades, pero ¿de qué manera ese Cristo que llegó históricamente a través del pueblo judío, que es judío, puede ser indio, puede ser maya? ¿De qué manera puede ser aceptado como salvador del pueblo maya un judío? Si Dios se hizo judío, ¿por qué no puede hacerse maya? ¿Dónde está el Cristo maya? Falta por elaborar la teología de la "siembra del Verbo" en las culturas indígenas.

El autor tiene la esperanza de poder derivar una cristología a partir de la teología de las semillas del Verbo, es decir, a partir de la revelación de Dios en la creación, tal como la percibe el pueblo maya. Pero esa pretensión equivale en teología, con todas sus buenas intenciones, a la pretensión del geómetra de cuadrar el círculo; equivale a la idealización de lo histórico. El drama del problema queda aún más acentuado por el hecho de que el autor lo plantea en relación con un pueblo y una cultura que ya ha sido largamente evangelizada, se confiesa cristiana y es profundamente creyente. ¿Qué decir en relación con pueblos y personas que pertenecen a culturas que no han sido evangelizadas? Con todo, el planteamiento del problema expresa una tremenda sensibilidad y respeto hacia las personas que viven de la cultura y las tradiciones religiosas del pueblo maya y presenta el problema en toda su crudeza.

Nuestro misionero imaginario liene que darse cuenta de una realidad: la evangelización es un fenómeno que pertenece a la categoría del diálogo intercultural. Independientemente del problema histórico de si la evangelización realizada en el pasado en diversas partes del mundo, comenzando por el mismo norte europeo, consistio en un avasallamiento cultural, el hecho es que hoy y para el futuro, las culturas ya no están aisladas, se influyen mutuamente y están en constante evolución, no sólo por la dinámica interna que las hace evolucionar, sino por el influjo de las culturas del mundo: la cultura tecnológica y científica occidental llega en forma de transporte, medicina, medios de comunicación social y los mensajes que los medios transmiten; las culturas de otros pueblos se conocen por el incremento de la migración en todos los sentidos. La evangelización viaja en la cresta de esa ola; siempre ha sido así, sólo que ahora tenemos conciencia de ello, todo ocurre a un ritmo más acelerado y pretendemos ser más cuidadosos. El mensaje evangélico -repetimos las palabras de Juan Pablo II- "se transmite siempre a través de un diálogo apostólico que está inevitablemente inserto en un cierto diálogo de culturas" (Catechesi tradendae, 53).

El anuncio de Jesucristo, como personaje histórico, de otro tiempo, de otra nación, de otra cultura, que, sin embargo, es salvador universal y, por tanto, también para cada pueblo y cultura concreto, es el problema básico de la evangelización consciente de la inculturación. Hay que encontrar la justificación antropológica y teológica que legitime el anuncio del evangelio como una propuesta de salvación procedente de otra cultura, pueblo y época. 
M. Gelabert se plantea ese problema en su artículo "La dialéclica del concreto universal en la evangelización"(6). La tesis que guía la reflexión del profesor dominico de la Facultad de Teología de San Vicente Ferrer de Valencia es que

el camino de la misión no es el que parte de un modelo y unos valores que supuestamente tendrían validez universal y que, por tanto, podrían trasplantarse en todos los pueblos, sino el que es capaz de realizar lo concreto de la revelación de Jesús como valor con significado universal y, por tanto, como capaz de entrar en comunión con otros valores y culturas concretas y de reconocer también en ellas la acción diferente del mismo y único Espfritu (p. 117).

En la tarea misionera, dice Gelabert, no se trata de transmitir valores absiractos: la justicia, la espiritualidad, el amor, la generosidad, ni siquiera la idea de Dios, valores que supuestamente tendrían vigencia universal. Esta es la tentación de la vena platónica del cristianismo. Se trata, más bien, de ofrecer el relato de una experiencia de revelación concreta e histórica, capaz de analogarse con experiencias de vida y revelación de otros pueblos y culturas.

Dada la condición histórica de la existencia humana, las realidades que transforman las posibilidades de realización del hombre han de ser acontecimientos históricos; las ideas y doctrinas tienen que hacerse acontecimiento y vida. La posibilidad de una opción vocacional no consiste en la idea de querer hacer tal o cual cosa, sino en la creación de las condiciones que hacen posible esa opción como realización de la propia vida. La posibilidad de la reconciliación no consiste en la idea del perdón, sino en la oferta efectiva de la paz y el perdón. La oferta de la vida eterna no consiste en la idea de la eternidad, sino en la apertura real de un pasillo a través de la muerte. La revelación de Dios tiene la característica de que se realiza como experiencia de salvación. Es decir, la revelación de Dios no consiste en el suministro de información acerca de Dios, que de otra forma serfa inaccesible y permanecería oculta. La revelación de Dios ha consistido en la efectiva realización de acciones que se viven y perciben como superación y salidas de males que agobiaban, como el logro de una mayor humanidad, como la posibilidad efectiva de alcanzar una plenitud de existencia. Porque el acontecimiento se percibe como salvador, liberador, plenificante, y además como graluito y no merecido o logrado por el propio esfuerzo. El hombre se pregunta por el sentido y consistencia de esos acontecimientos. $\mathrm{Y}$ al interrogarse, intuye y descubre en ellos la acción de Dios, conoce a Dios. Dios se revela en sus actos salvificos y la experiencia de la salvación es el efecto de la voluntad de Dios de darse a conocer. La doctrina, secundaria con relación a la experiencia, es el intento de elaboración conceptual de esta experiencia. Porque la revelación de Dios es experiencia salvffica, tiene carácter histórico; o dicho desde una

6. En D. Salado (Coord.), Inculsuración y nueva evangelización (Salamanca 1991), pp. 115-132. 
perspectiva antropológica, porque la religión judeocristiana conoce a Dios a través de acontecimientos históricos que experimenta como salvíficos, esos acontecimientos están condicionados por las limitaciones de lo histórico. En la lógica de esa tradición, la oferta de salvación de valor definitivo y universal ocurrió en un acontecimiento historico que también fue reconocido como la máxima y definitiva revelación de Dios. Como afima Gelabert,

si lo pensamos bien, resulta que sólo los fenómenos situados en el tiempo y en el espacio pueden ser alcanzados por el hombre y afectarle realmente. Por tanto, el único modo de ser universal es a partir de la concreción histórica (p. 123).

La pregunta que se nos plantea, entonces, es doble, ¿en qué consiste fundamentalmente la revelación-salvación que se dio en Jesucristo y de qué manera es transmisible esa revelación concreta a la humanidad de todo tiempo y lugar?

En Jesús de Nazaret se revela primariamente una experiencia de Dios como Padre misericordioso, quien, por medio de Jesús, realiza la acción salvadora por la que devuelve al enfermo la salud, al pobre la dignidad, al pecador la paz, al prisionero la liberlad, al muerto la vida, comenzando por el mismo Jesús. Jesús revela a Dios por medio de su propia experiencia de vida; por eso, el evangelio no es un catecismo, sino un relato. La propuesta que hace Jesús es vivir en referencia al reino de Dios, como vivió él; su enseñanza no consiste nunca en especulaciones sobre Dios, el mundo o el hombre, sino en propuestas de vida. Quien vive como él vivio, conoce a Dios, y, conociéndolo, se salva. Esta es la palabra de Jesús en el evangelio de san Juan, el más consciente de la realidad histórica de Jesús como determinante para el sentido definitivo de la vida de los demás hombres: "Yo soy el pan de vida. El que viene a mí no volverá a tener hambre; el que cree en mí nunca tendrá sed" $(6,35) ;$ "Yo soy la luz del mundo. El que me sigue no caminará a oscuras, sino que tendrá la luz de la vida" (8, 12); "Yo soy el camino, la verdad y la vida. Nadie puede llegar hasta el Padre, sino por $m \int^{\prime \prime}(14,6)$.

La transmisión de la revelación realizada por Jesús consiste en la oferta de la presencia del Espíritu y de una forma de vida, ejemplificada en el evangelizador, mejor aún, en la comunidad evangelizadora. Esta oferta de vida tiene como referencia externa el ejemplo de Jesús y como consistencia interna la acción del Espíritu. El evangelizador, en efecto, no ofrece el relato de la historia de Jesús como una información "a quien interese", sin que le afecte a él. El evangelizador más bien ofrece la alegría y la plenilud de su vida como testimonio de la presencia transformadora del Espiritu de Jesús, estando disponible al pobre, al pecador, al enfermo, al desesperado, al marginado, gracias a la obra de Jesús, confirmada por su resurrección y por el don del Espíritu. Y como explicación de su alegría y esperanza, ofrece el relato acerca de Jesús. Concluye Gelabert, citando a E. Schillebeeckx: 
Pues no hay nada más universal que aquello que hace al hombre feliz y plenamente humano: "toda llamada a una auténtica humanidad tiene por naturaleza un significado universal" (p. 127).

La apropiación que cada cultura haga del relato de la vida de Jesús, qué aspectos subraye porque responden a su experiencia histórica y humana, con qué conceptos entienda la realidad de Jesús, constituye el proceso de inculturación. Es inevitable y necesario que la comunidad evangelizada conozca las formas como la comunidad eclesial, a lo largo de su historia, ha expresado y comprendido a Jesús. Es necesario que la comunidad evangelizada aporte desde su cultura nuevas expresiones, nuevas perspectivas que permitan traer a la luz las riquezas del misterio de Dios revelado en Jesús. Pero esta tarea de apropiación del evangelio desde la perspectiva de la cultura particular plantea de lleno el problema eclesiológico.

\section{El reto eclesiológico}

Los pueblos se caracterizan y distinguen por las culturas. Es verdad que hay una base étnico-biológica que permite distinguir grupos raciales en el conjunto de la humanidad. Estos grupos raciales son originarios de lugares geográficos concretos, por lo que, parece que a los diversos grupos raciales corresponde una cultura específica, pero en realidad, los dos aspectos de la antropología son independientes. Dentro de un mismo grupo racial pueden darse diversas culturas. Y gracias a las migraciones, los grupos raciales ya no están geográficamente ubicados de forma exclusiva, sino que asistimos a una gran mezcla de las razas humanas, en un grado nunca visto hasta ahora, de modo que personas pertenecientes a razas distintas pueden ser portadoras de la misma cultura. Hago esta aclaración, que a algunos puede parecer obvia, para superar desde el inicio el prejuicio de que los comportamientos culturales de un pueblo dependen de su raza y son irreformables.

Las formas culturales, por otra parte, no son realidades estáticas ni cerradas. Las culturas evolucionan, con mayor o menor aceleración y velocidad, pero evolucionan. Las razones de la evolución cultural son la aparición de nuevas necesidades sociales o de nuevos recursos disponibles para la comunidad, lo que conduce a la revisión de prioridades y de formas de conducta para el aprovechamiento del recurso. Las culturas también cambian por el contacto con otras culturas, sea por las migraciones, o por el comercio o por las comunicaciones en general, que permiten conocer nuevos modos de hacer las cosas que resultan atractivos porque son más ventajosos que los conocidos en la propia cultura o dan un aura de prestigio social. Esta afirmación no es un juicio ético, sino una constatación de hecho. En verdad, muchos de los cambios culturales inducidos por imitación de otras culturas, a veces imitan lo peor y más deshumanizante. Pero éstos son procesos cuyo curso no se puede forzar desde la autoridad, sino 
que sólo se pueden guiar desde la creación de convicciones socialmenle admitidas.

Cuando hablamos de las culturas de los pueblos, debemos estar siempre conscientes de que no hablamos de realidades fijas y anquilosadas, sino de realidades dinámicas y cambiantes. El terreno cultural no es tierra firme, sino río corricnte. Por eso, las personas nunca están al servicio de la cultura, sino la culrura al servicio de las personas. Cuando a veces se dan esfuerzos tendientes a la conservación o recuperación de rasgos culturales (la lengua, por ejemplo), esos esluerzos son viables solamente si tienen una función socialmente reconocida, como puede ser la necesidad de la comunidad de conservar o reafirmar su identidad ante algún tipo de agresión social. Ningún pueblo conserva rasgos culturales que considera caducos por razones científicas o sentimentales; ése es el empeño de antropólogos e historiadores de la cultura. La identidad cultural de un pueblo no consiste en el mantenimiento de formas culturales, sino en la memoria de la propia historia.

Por eso, no debe causar alarma la afirmación de que la evangelización es un factor de transformeción culrural. Además, es un agente de transformación con pretensiones de llegar a la médula donde se gestan las formas culturales, pues la evangelización hace una propuesta en torno a las preguntas fundamentales sobre el origen y el destino del hombre como persona y como sociedad, sobre el sentido del mundo y sobre la responsabilidad ética, es decir, la pregunta sobre el bien y el mal. Estas son las preguntas a las que responden las culturas en sus estructuras más profundas y en sus manifestaciones más espirituales. La evangelización, al ofrecer una propuesta como buena nueva, pretende que los pueblos, al aceptarla, transformen aquella comprensión de sí mismos que no es coherente con el evangelio $\mathrm{y}$, al hacerlo, transformen aquellas formas culturales que implican incoherencia con la propuesta de Jesús. En palabras de Juan Pablo II,

la fuerza del Evangelio es en todas partes transformadora y regeneradora. Cuando penetra una cultura, ¿quién puede sorprenderse de que cambien en ella no pocos elementos? No habrfa catequesis si fuese el Evangelio el que hubiera de cambiar en contacto con las culturas (Catechesi tradendae, 53).

Ahora bien, estas afirmaciones parecen decir todo lo contrario de lo que se entiende cuando hablamos de inculturación. Normalmente, al hablar de la necesidad de la inculturación como criterio de la evangelización entendemos que ésta debe hacerse de tal forma que la cultura no cambie, que la evangelización no suponga la importación de las formas culturales del evangelizador, que la evangelización no altere los usos sociales de los pueblos evangelizados. En realidad, la inculturación no trata de estas cosas; una inculturación así comprendida es preocupación de antropologos y lingüistas dispuestos a sacrificar a las personas en aras de la etnología. La inculturación, como criterio de evangelización, no tiene su interés primario en la preservación de las culturas, sino que presta atención a las culturas y respeta las culturas desde el respeto a las personas. La 
evangelización tiene como referencia la cultura, no para que permanezca inalterada, sino como expresión del hondo respeto que debe a las personas que se identifican con una cultura dada, respeto que debe guiar toda evangelización. En segundo lugar, la evangelización tiene como referencia la cultura, para descubrir en ella aperturas para la oferta que viene a hacer y para lograr que la buena nueva que viene a traer sean comprendidas desde los presupuestos culturales del evangelizado y no desde los condicionamientos culturales del evangelizador.

Los factores que constituyen una cultura y los medios que la expresan tienen diversos niveles de incidencia e importancia. Se ha hecho célebre la definición de cultura que hacían los obispos latinoamericanos en Puebla:

Con la palabra "cultura" se indica el modo particular cómo, en un pueblo, los hombres cultivan su relación con la naturaleza, entre sí mismos y con Dios (GS 53b) de modo que puedan llegar a "un nivel verdadera y plenamente humano" (GS 53a). Es "el estilo de vida común" (GS 53c) que caracteriza a los diversos pueblos; por ello se habla de "pluralidad de culturas" (GS 53c) (Documento de Puebla 386).

Esta definición, basada en la que daba la Constitución Gaudium et spes, 53, ve la cultura como el medio que estructura las relaciones que las personas en una comunidad determinada tienen para con la naturaleza o el mundo, para con los otros hombres y para con Dios. Si tenemos en cuenta que ésas son las realidades fundamentales con las cuales tiene que habérselas el ser humano personal y comunitariamente, y que además el evangelio tiene unas propuestas muy concretas y específicas de cómo deben entenderse esas relaciones, es evidente que la evangelización lleva implícita una propuesta cultural.

Dicho esto, queda claro que el criterio de inculturación, como criterio pastoral de evangelización, dimana de una preocupación profundamente respetuosa de la persona y de la comunidad evangelizada. Se trata de que las personas y las comunidades humanas destinatarias de la evangelización aceplen y acojan el evangelio como una mejor respuesta y solución a las interrogantes y aspiraciones de salvación, porque abre de forma efectiva a una plenitud de vida y de sentido; y de que acepten y acojan el evangelio desde las preguntas y cuestionamientos que se plantean desde la propia cultura. De lo que se trata es de que el Evangelio no sea nunca "un barniz"- son palabras de Pablo VI (Evangelii nuntiandi, 20)-, puesto desde fuera, pero que no responde a los cuestionamientos y esperanzas de los evangelizados, porque o ha sido impuesto a la fuerza o sigue siendo presentado en formas, conceptos y ritos que responden a otras preocupaciones culturales ajenas a las de los evangelizados.

Una evangelización que está atenta a la cultura está abocada a la diversificación de las formas en que el evangelio es entendido, acogido y expresado. No porque el evangelio cambie para acomodarse a cada cultura, sino porque cada 
comunidad humana lo acoge y lo expresa, haciendo énfasis en diversos aspectos, celebrándolo en distintos ritos, comprendiéndolo con distintos conceplos. Surgen asf comunidades creyentes en el mismo evangelio, pero que lo entienden, lo viven y lo celebran de diversas maneras. La afirmación no es hipotética, es histórica. Este fue el resultado de la evangelización del oriente antiguo, donde surgieron de la iglesia de lengua griega las iglesias siríaca, armenia, persa y malabar primero, y luego, ya en el siglo IX, las iglesias de los pueblos eslavos(7). Las misiones llevadas a cabo por la Iglesia latina no fueron tan sensibles a las culturas locales como lo había sido la Iglesia griega, quizá siguiendo en esto el patrón colonial de la política imperial romana en occidente(8).

7. La encíclica de Juan Pablo Il Slavorum aposioli (2 de junio de 1985) con ocasión de los 750 años de la muerte de san Cirilo, presenta la evangelización de los pueblos eslavos por los griegos Cirilo y Melodio como modelo de evangelización atenta al factor de la cultura. "Las tradiciones propias de muchas iglesias nacionales de oriente -como la georgiana y la sirfaca- que en el servicio divino usaban la lengua de su pueblo, eran bien conocidas a la cultura superior de Constantinopla y, especialmente. a Constantino Filosofo, gracias a los estudios y a los contactos repetidos que habfa tenido con el cristianismo de aquellas iglesias, tanto en la capital como en el curso de sus viajes. Ambos hermanos, conscientes de la antiguiedad y de la legitimidad de estas sagradas tradiciones, no tuvieron pues miedo de usar la lengua eslava en la liturgia, haciendo de ella un instrumento elicaz para acercar las verdades divinas a cuantos hablaban en esa lengua" (12).

8. P. Aguirrebalzategi dice en Configuración eclesial de las culturas: "El reino de los seléucidas, en su intento de helenizar los innumerables pueblos de sus condominios, construyeron muchísimas ciudades griegas, en las que haclan participar también a los indigenas. Con todo, lo que consiguió en la parte más occidental, no alcanzó a realizarlo en el interior. En efecto, en el inmenso reino, las ciudades griegas resultaban muy pocas para asimilar los pueblos enteros. De hecho, los diversos pueblos conservaron su identidad lingülstica, religiosa y cultural en general, aun después de la conquista de los romanos, aunque el arameo se había extendido notablemente. En este mundo cultural no contagiado verdaderamente por la cultura griega, surgen lo que se han llamado las "iglesias nacionales", en confliclo político religioso con el imperio y las cristiandades griegas" (p. 140). "La situación cultural de la parte occidental del Imperio es diversa. No han existido las grandes civilizaciones del oriente ni se ha creado la ekwmene del helenismo. [...] Aquí Cartago había perdido su personalidad antigua, convirtiéndose en floreciente colonia romana y romanizada; la Hispania, la Gallia, Rhenania, parte de la Anglia, frente al poder y organización polftico-cultural de Roma habian sido igualmente romanizadas cultural y lingüisticamente, en la medida en que la presencia romana se hacia más considerable. En todo caso la dinámica cultural de la parte occidental del imperio es prácticamente de un único signo y en una única dirección desde el centro de Roma. De todos modos, no es la lengua el elemento fundamental que distingue la civilización latina de la helénica, sino las instituciones" (pp. 142-143). "Las iglesias de Hispania, por una parte, las de la Gallia, Rhenania y Anglia, por otra, forman diversas unidades, no independientes de Roma, 
La evangelización de por sí, pues, no es un proyecto de uniformidad, sino de diversidad. Sin embargo, como la evangelización lleva en sí misma la meta de la unidad en la fraternidad, la solidaridad y el amor, el reto eclesiológico consiste en el desafío de mantener la unidad de la iglesia de Cristo a través de la multiplicidad de formas en que se concreta y existe. Es el problema de la comunión de las iglesias particulares en la única iglesia de Cristo.

La iglesia particular es el fundamento eclesiológico de la tarea de la inculturación, en cuanto que ésta se define precisamente por las realidades geográficas y culturales que identifican una comunidad humana concreta. Es la forma como se ha configurado históricamente la presencia de las comunidadés de discípulos en el mundo, a causa precisamente de la diversidad geográfica, cultural, polf́tica e histórica de los pueblos evangelizados. En efecto, las primeras comunidades creyentes establecidas por los apóstoles eran, cada una, la Iglesia de Cristo en su totalidad e integridad. Sin embargo, el conjunto de comunidades no constituían muchas iglesias de Cristo, sino la única y misma Iglesia. Pablo VI corrobora este proceso histórico por el que han surgido las iglesias particulares como concreción de la Iglesia de Cristo:

Esta Iglesia universal se encarna de hecho en las iglesias particulares, constituidas de tal o cual porción de la humanidad concreta, que hablan tal lengua, son tributarias de una herencia cultural, de una visión del mundo, de un pasado histórico, de un substrato humano delerminado (Evangelii nuntiandi, 62).

Es cierto que el concepto de Iglesia particular que manejamos usualmente es el concepto canónico:

n. 368. Iglesias particulares, en las cuales y desde las cuales existe la Iglesia católica una y única, son principalmente las diócesis.

n. 369. La diócesis es una porción del pueblo de Dios cuyo cuidado pastoral se encomienda al Obispo con la colaboración del presbiterio, de manera que, unida a su pastor y congregada por él en el Espíritu Santo mediante el Evangelio y la Eucaristía, constituya una Iglesia particular, en la cual

pero con su personalidad y autonomía. Sin embargo, se puede decir que son cristiandades "importadas" desde Roma, no creadas; su originalidad y dependencia de expresión eclesial es del mismo grado que la originalidad y la dependencia cultural de los pueblos occidentales respecto de Roma. En efecto, la Iglesia se ha desentendido casi completamente de las lenguas "bárbaras" del imperio occidental, y en su difunsión han seguido el proceso difusivo de la lengua y la cultura latina, según la corriente de aculturación desde Roma hacia el exterior" (p. 144). Juan Pablo II dice en Slavonum apostoli, "El cristianismo occidental, después de las migraciones de los pueblos nuevos. había amalgamado los grupos étnicos llegados con las poblaciones latinas residentes. extendiendo a todos, con la intención de unirlos, la lengua, la liturgia y la cultura latina transmitidas por la Iglesia de Roma" (12). 
verdaderamente está presente y actúa la Iglesia de Cristo una, santa, católica y apostólica.

Ahora bien, entre la realidad histórica y concreta de la Iglesia particular y la realidad mistérica y efectiva de la Iglesia única y católica hay una tensión dialéctica: la una y la otra están imbricadas de modo que la Iglesia única y católica existe en y desde las iglesias particulares, pero a su vez la Iglesia particular, mientras tiene la misión de arraigar en un pueblo y lugar, no puede dejar de reconocer que la realidad de su misterio es único y católico y se realiza también en las concreciones específicas de las demás iglesias particulares. La tragedia y el drama, especialmente en la Iglesia latina, es que siendo la Iglesia con mayor impulso misionero y fuerza expansiva, ha pretendido realizar la comunión a través de la uniformidad, al precio de sacrificar la particularidad a través de la inculturación.

Veamos, primero, la misión de la Iglesia particular en cuanto tal. La Iglesia particular tiene la tarea de arraigar en un pueblo, asumiendo su cultura. La Iglesia particular habla, en primer lugar, la lengua del pueblo. La Iglesia particular es sensible a las expresiones religiosas autóctonas y a las propias de la cultura, pues son las aperturas que la cultura ofrece a la pregunta acerca de Dios y de la salvación humana. La Iglesia particular acoge el evangelio de Jesús desde los condicionamientos sociopolíticos de cada comunidad concreta. La Iglesia particular sabe que el evangelio que recibe es una experiencia de salvación vivida y realizada en una cultura específica (la judeo-helenista del siglo I), pero ofrecida a la humanidad y a cada hombre y mujer y comunidad humana concreta como posibilidad definitiva y plena de salvación; pero la Iglesia particular al acoger el evangelio de Jesús lo asume desde su cultura concreta. En este proceso se deja corregir por el evangelio en aquellas realidades míticas y religiosas, éticas y filosóficas, sociales y organizativas que no son coherentes con el evangelio; pero a su vez, de su propia riqueza, aporta sus experiencias religiosas, filosóficas, éticas y sociales, que expresan adecuadamente el evangelio.

Ciertamente es muy fácil hablar de esto en abstracto. Mucho más difícil es discernir si este mito, esta experiencia de Dios, este rito y esta costumbre concreta son aplas porladoras del evangelio y expresión adecuada del mismo. Es frecuente la queja de que los papas hablan con gran audacia sobre la inculturación en abstracto, pero son sumamente timoratos en aprobar las aplicaciones concretas de los proyectos de inculturación de las iglesias particulares. La tensión entre la audacia y la prudencia es componente ineludible del proceso, porque la Iglesia particular no sólo tiene la obligación de particularizarse cada vez más, sino que tiene la responsabilidad de mantenerse en la comunión.

Este es el otro polo del desaffo eclesial. La Iglesia particular sabe que la realidad mistérica que constituye su identidad profunda, es decir, la presencia de Cristo resucitado en su seno por medio del Espíritu para la gloria del Padre y 
salvación del hombre, esa realidad, no es posesión exclusiva suya, sino que la comparte con las otras iglesias particulares, de otros lugares y culturas, e incluso de otras épocas pasadas, por lo que se impone la necesidad de un reconocimiento mutuo: las muchas iglesias particulares están en comunión por su identidad como Iglesia católica. Por lo tanto, la Iglesia particular tiene la responsabilidad de acoger el misterio que recibe en la evangelizacion, conservando la identidad de ese misterio, pues este esfuerzo es lo que le permite a la Iglesia particular realizarse como Iglesia de Cristo. Por tanto, el proceso de inculturación del evangelio no puede realizarse de tal modo que la identidad quede comprometida. La prueba de que esto ha sido logrado es el reconocimiento que las otras iglesias particulares hagan de lo que esta Iglesia particular concreta expresa en sus formas culturales. Es el mismo misterio de salvación compartido por todas. Las iglesias particulares tienen unas con otras la responsabilidad de acogerse y reconocerse en la comunión de fe, de esperanza y de amor. En la concepción calólica, esa responsabilidad la tiene principalmente la Iglesia particular de Roma y su obispo hacia las demás iglesias, y éstas entre sı y con la de Roma. La comunión episcopal en el colegio de los obispos expresa orgánicamente la comunión de las iglesias y la celebración de la eucaristía la realiza sacramentalmente. Pablo VI llamaba así la atención acerca de la importancia de mantener la doble referencia:

La evangelización pierde mucho de su fuerza y de su eficacia, si no toma en consideración al pueblo concreto al que se dirige. Si no utiliza su "lengua", sus signos y símbolos, si no responde a las cuestiones que plantea, no llega a su vida concreta. Pero, por otra parte, la evangelización corre el riesgo de perder su alma y desvanecerse, si se vacla o desvirtúa su contenido, bajo pretexto de traducirlo; si queriendo adaptar una realidad universal a un espacio local, se sacrifica esta realidad y se destruye la unidad sin la cual no hay universalidad. Ahora bien, solamente una Iglesia que mantenga la conciencia de su universalidad y demuesire que es de hecho universal puede tener un mensaje capaz de ser entendido, por encima de los límites regionales, en el mundo entero (Evangelii nuntiandi 63). Por lo mismo, una Iglesia particular que se desgajara voluntariamente de la Iglesia universal perdería su referencia al designio de Dios y se empobrecería en su dimensión eclesial. Pero, de otra parte, la Iglesia "difundida por todo el orbe" se convertiría en una abstracción, si no tomase cuerpo y vida precisamente a través de las iglesias particulares. Sólo una atención permanente a los dos polos de la Iglesia nos permitirá percibir la riqueza de esta relación entre la Iglesia universal e iglesias particulares (Ibid. 62).

\section{El proyecto pastoral}

En esta cuarta y última sección de este artículo quiero abordar asuntos prácticos de mayor incidencia en la comprensión de la inculturación como tarea y reto pastoral. Búsicamente hay que identificar los retos específicos que nos 
plantean las diversas culturas en las que se debe realizar la evangelización. Pero, ¿de qué culturas estamos hablando?

Toda la exposición ha sido hecha bajo el supuesto de la evangelización de pueblos y comunidades pertenecientes a una cultura diversa de la del evangelizador. En concreto, hemos mantenido el supuesto de que tratábamos de la evangelización de pueblos con culturas diversas de la cultura occidental europea. Ese es el caso más ilustrativo, y constituye un peso en la conciencia de la Iglesia católica en relación con la evangelización realizada en los pueblos de culturas aborígenes de América principalmente, y Africa y Asia en menor grado.

Las poblaciones autóctonas o indigenas presentan, a mi modo de ver, un reto peculiar. Estoy más familiarizado con el caso de Centroamérica, de Guatemala y Panamá especialmente. Son pueblos que constituyen la mayoría en Guatemala, que han conservado la propia lengua y con ella una forma cultural propia. Han estado política y económicamente marginados. En Guatemala, activamente marginados; en Panamá, quizá simplemente aislados. Ante la presión de la cultura occidental y la política excluyente y discriminatoria han creado como rasgo cultural la resistencia. Sin embargo, este siglo es testigo de un desarrollo cultural significativo. El desarrollo de las comunicaciones y el contacto más amplio y de propia iniciativa con la cultura y la economía occidental de sus respectivos países ha llevado a la creación de una conciencia histórica y de identidad, que se traduce en reivindicaciones culturales y políticas. La identidad se busca en una legítima idealización del pasado para reafirmar la propia dignidad como pueblo, en la defensa de la propia lengua, en la recuperación de las religiones ancestrales, en reclamos territoriales, en la exigencia de reconocimiento estatal de su derecho consuetudinario y en una mayor autonomía política. Es imposible predecir cuál será el resultado de este esfuerzo; creo que alcanzará su meta en la forma de un espacio cultural peculiar dentro de la cultura latinoamericana.

Estas culturas no son paganas, son cristianas. La población indígena guatemalteca es católica. El reto pastoral en estas culturas consiste, primero, en la acogida y la sanción de ritos, costumbres, concepciones religiosas, formas ministeriales y organizativas en las que el cristianismo ha quedado asumido popularmente a partir del mundo religioso ancestral y tradicional. En segundo lugar, en el diálogo con los portadores de las formas religiosas en que ha evolucionado clandestinamente una religión autóctona que echa sus raíces en las religiones precolombinas. En tercer lugar, el reto se presenta a los miembros no indigenas de estas iglesias particulares indígenas (que son con frecuencia los sacerdotes y los religiosos y un grupo minoritario de laicos) para que desarrollen la sensibilidad a los reclamos y las reivindicaciones de los pueblos autóctonos y los acompañen en las transformaciones culturales por las que actualmente transitan. Por último, la liturgia debe aprender a hablar los idiomas de la mayoría de los miembros de la Iglesia; el diálogo teológico debe discernir el mundo 
simbólico, mítico y religioso; la autoridad eclesial debe asumir cuanto demuestre ser una adecuada expresión de la fe.

En los últimos años se han dado pasos importantes en el diálogo entre el cristianismo y las formas religiosas indígenas. Ahí están el primer y segundo "Encuentro taller latinoamericano de teología india", celebrados en México, en 1990, el primero, y en Panamá, en 1993, el segundo. Además, en el área mayense, se han realizado diversos encuentros de "Teología india mayense", en San Cristóbal de las Casas, Chiapas, en 1991; en Chichicastenango, en 1992(9). En todos ellos se han reunido obispos, sacerdotes y laicos católicos, hombres y mujeres, sin dejar de participar sacerdotes de las religiones autóctonas. Han sido verdaderos ejercicios de diálogo y escucha.

En el primer encuentro-taller de teologia india se hizo el discemimiento en torno al concepto mismo de teología india: "Es la comprensión que tenemos de nuestra vida entera guiada siempre por la mano de Dios. Es el discurso reflexivo que acompaña, explica y guja el caminar de nuestros pueblos indios a través de toda su historia"(10). Es, en definitiva, el intento por articular de forma sistemática la interpretación religiosa de la vida tal como la viven los pueblos indígenas. Es importante destacar la toma de distancia que esta teología india realiza con respecto de la teología de la liberación. En el primer encuentro de teología india de la región mayense se tomó conciencia de la diferencia:

Ciertamente en la teología india no reducimos la problemática de nuestros pueblos a la categoría de pobres o explotados a nivel económico, y en consecuencia, necesitados básicamente de una liberación económica. Ser pobres y explotados es sólo parte de la realidad india. Los indios somos además portadores de un proyecto de vida que heredamos de nuestros

9. Véase la siguiente bibliografla: Teología india: Primer encuentro caller latinoamericano, México (16 al 23 de sepliembre de 1990). CENAM1, 1992; Teologia india: Segundo encuentro-taller latinoamericano (Panamá 29 de noviembre al 3 de diciembre de 1993) CENAMI, México 1994. Teología india mayense: memorias, experiencias y reflexiones de encuentros reológicos regionales, CENAMI, 1993. EI III Encuentro de teologja india maya tuvo lugar en Guatemala, del 3 al 7 de junio de 1996. Se centró en el estudio de milos y símbolos mayas desde la perspectiva teologica.

10. Teologla india: Primer encuentro, p. 7. Es interesante que se haya adoptado el adjetivo "india" para calificar esta teología. La palabra "indio", como se sabe, es denigratoria e injuriosa por despectiva; la inventaron los europeos para referirse a las poblaciones aborigenes de América. Sin embargo, al asumirla como adjetivo que califica a la reflexión teológica y, por lo tanto, el discurso más sublime porque toca la médula de las creencias vitales, los indígenas americanos están realizando una tarea de redención del pasado por el rescate de la palabra, pues, al asumirla, asumen el pasado de opresión y marginación expresado en la palabra, y así dignifican el pasado y exorcizan la palabra de los demonios semánticos de desprecio y discriminación de los que estó poselda. 
antepasados y que vamos cargando, custodiado celosamente en nuestras culturas y formas religiosas propias.

Pensamos que la teología india está encaminada básicamente a consolidar el ser más profundo de nuestros pueblos, para que vivamos no sólo mejor, sino que vivamos como nosotros mismos, con nuestro propio rostro y corazón de pueblos diferenciados, dando cauce histórico a nuestros proyectos de vida. [...] De alguna manera se podría decir que la teología de la liberación se ha preocupado hasta ahora por la parte material del hombre. En tanto que la teología india se preocupa por la parte espiritual del pueblo, sin descuidar la parte material. Por eso su espacio de lucha es sobre todo la cultura y la religión(1 I).

El segundo encuentro taller se centro más bien en compartir y explicar las ideas y los nombres de Dios en las diversas lenguas y culturas del continente. En las palabras conclusivas, los participantes indígenas afirmaban: "En ambiente de oración y alrededor de los símbolos sagrados de nuestros pueblos, invocamos a Dios y hablamos de $\mathrm{El}$ como madre-padre con los nombres que nuestros antepasados nos enseñaron; nombres que lo muestran estrechamente unido a la vida, a la ternura, al amor, a la comunidad, a la armonía con el mundo"(12).

En los aportes y las discusiones realizadas en estos encuentros taller hay una enorme variedad de posiciones. Es muy diverso el grado en que se explicita o se silencia la dimensión cristiana del discurso, a pesar de que la mayoría de los participantes son cristianos. Queda pendiente el reto de esclarecer la forma en que se asimila a Jesucristo como portador de la revelación histórica plena de Dios, y que, sin embargo, viene de fuera, de los judíos.

Creo que es oportuno recordar en esla coyuntura algunas indicaciones de Juan Pablo I en la carta encíclica Redemptoris missio. La inculturación es un proceso de ritmo lento, pues se fragua en los estratos profundos de la cultura y de las personas. Hace falta, por lo tanto, paciencia y respelo. No es un proceso de técnicos y expertos, sino comunitario; no puede ser forzado ni acelerado, sino que debe ser estimulado y acompañado en sus cadencias. Los agentes de pastoral extranjeros a la cultura muestran respeto y cariño por los pueblos evangelizados a quienes sirven, aprendiendo su lengua, descubriendo sus valores y asumiendo estilos de vida solidarios y evangélicos(13).

11. Teología india mayense, p. 51.

12. Teologia india segundo encuentro, p. 184.

13. "El proceso de inserción de la Iglesia en las culturas de los pueblos requiere largo tiempo: no se trata de una mera adaptación extema, ya que la inculturación "significa una intima transformación de los auténticos valores culturales mediente su integración en el cristianismo y la radicación del cristianismo en las diversas culturas" (Asamblea extraordinaria del sínodo en 1985, Relación final, II, C. 6). Es, pues, un proceso 
Hay que evitar confundir el "folklorismo" con la inculturación. Vestir ornamentos cortados en la sastrería de liturgos e historiadores del vestido, introducir en la celebración sin previa reflexión comunitaria danzas y ritos locales y sustituir arbitrariamente el pan y el vino por tortillas y chicha fuerte no son por sí solos inculturación, por más que la celebración tenga un aspecto localista y "típico". La inculturación tiene que ver más con la dinamización de la educación y de la cultura, de la sociedad y de las estructuras civiles por la fe y el evangelio, que con la adopción de objetos culturales para la liturgia sin que cl evangelio fecunde la vida y los valores del pueblo. La inculturación no surge del atrevimiento y las improvisaciones, sino de la comprensión y el respeto; la inculturación no comienza por lo sensible y externo, sino que surge de la interioridad de la fe comúnmente aceptada que busca expresarse en los valores y principios que rigen y guían la cultura y las esiructuras sociales, y recurre a las palabras, los símbolos, el arte y la música de la propia cultura para expresar la fe vivida.

El tema de la inculturación, aunque comúnmente se refiere a la evangelización de las culturas no occidentales, es un criterio de evangelización mucho más amplio e impregna todo el quehacer pastoral de la Iglesia. De hecho, la misma Iglesia europea y occidental, inculturada en una cultura rural y agrícola y de cristiandad, confronta actualmente el desafío de evangelizar una cultura posmoderna, urbana, industrializada y secularizada. El mismo Juan Pablo I, en la enciclica Redemptoris missio, insiste en que la misión ad gentes, es decir, "a

profundo y global que abarca tanto el mensaje cristiano, como la reflexión y la praxis de la Iglesia. [...] Por medio de la inculturación, la Iglesia encama el evangelio en las diversas culturas y, al mismo tiempo, introduce a los pueblos con sus culturas en su misma comunidad; transmile a las mismas sus propios valores, asumiendo lo que hay de bueno en ellas y renovándolas desde dentro" (52). "Los misioneros, provenientes de otras iglesias y paises, deben insertarse en el mundo sociocultural de aquellos a quienes son enviados, superando los condicionamientos del propio ambiente de origen. AsI deben aprender la lengua de la región donde trabajan, conocer las expresiones más significativas de aquella cultura, descubriendo sus valores por experiencia directa. [...] Para ellos no se trata ciertamente de renegar a la propia identidad cultural, sino de comprender, apreciar, promover y evangelizar la del ambiente donde actúan y, por consiguiente, estar en condiciones de comunicar realmente con él, asumiendo un estilo de vida que sea signo de testimonio evangélico y de solidaridad con la gente" (53). "A este respecto, son fundamentales algunas indicaciones. La inculturación, en su recto proceso, debe estar dirigida por dos principios: 'la compatibilidad con el evangelio de las varias culturas a asumir y la comunión con la Iglesia universal' (Exh. Ap. Familiaris consortium, 10) ... Este proceso necesita una gradualidad, para que sea verdaderamente expresión de la experiencia cristiana de la comunidad ... Finalmente, la inculturación debe implicar a todo el pueblo de Dios, no sólo a algunos expertos, ya que se sabe que el pueblo reflexiona sobre el genuino sentido de la fe que nunca conviene perder de vista. Esta inculuuración debe ser dirigida y estimulada, pero no forzade, para no suscitar reacciones negativas en los cristianos". 
los pueblos o grupos humanos que todavía no creen en Cristo, a los que están alejados de Cristo, entre los cuales la Iglesia no ha arraigado todavía" (34), es una misión especlfica y peculiar de la pastoral de evangelización. Pero señala que existe una situación intermedia, especialmente en los países de antigua cristiandad, pero a veces también en las iglesias más jóvenes, donde grupos enteros de bautizados han perdido el sentido vivo de la le o incluso no se reconocen ya como miembros de la Iglesia, llevando una existencia alejada de Cristo y de su evangelio. En este caso es necesaria una "nueva evangelización" o "reevangelización" (33).

La cultura latinoamericana representa una variante importante de la cultura occidental. Basta para demostrarlo el hecho de que habla lenguas europeas occidentales: español, portugués y francés como lengua madre y no como segunda lengua o lengua franca. En esto nos distinguimos netamente de los países de Asia y Africa, que hablan lenguas europeas (francés o inglés) como lengua culta, lengua franca, lengua pública, pero que conservan vigorosos y reivindicativos los idiomas autóctonos. La población aborigen de América que conserva lenguas propias nos confronta con un desafío cultural de otra f́ndole, y ya hemos hablado de ello: representa un aspecto del problema de la evangelización de América Latina.

Creo que el factor diferenciador de la cultura occidental latinoamericana es la historia socio-política y económica de la región. La cultura occidental llegó a América latina como fruto de un proyecto colonial, económico y migratorio de Europa. Desde el principio, la cultura de la población emigrante siguió mirando hacia afuera como el lugar en donde se gesta y se crea su desarrollo. Por oura parte, el grado de familiaridad y asimilación de la cultura occidental en la población criolla y mestiza ha dependido del estrato social al que se pertenece: los estralos económica y políticamente más solventes han sido y siguen siendo los más occidentalizados. América Latina carece de la homogeneidad cultural que caracteriza a la población europea. Por otra parte, la sociedad latinoamericana se gestó como una organización colonial, donde las decisiones politicas y económicas se tomaban en ultramar. Los movimientos de independencia significaron el traslado de dicha autoridad a las clases económicamente más solventes de la población que, sin embargo, salvo quizá en los paises en donde casi toda la población es inmigrante y casi no hay mestizaje con población autóctona, como Argentina, Chile o el sur del Brasil, continúa con una dependencia cultural y económica en relación con Europa o con Estados Unidos.

El fenómeno cultural de la secularización, que caracteriza la evolución de la cultura occidental en Europa, se da, por lo tanto, de forma muy desigual en América latina. En aquellas regiones, como Centroamérica, donde hay una población mestiza y campesina (no industrializada) y autóctona (marginada) significativa, la cultura está minimamente afectada por la actitud críca y científica 
de la cultura occidental; tiene vigencia la interpretación religiosa y humanizante de la realidad. Pero aquí hay una responsabilidad de la evangelización, que no consiste, a mi modo de ver, en "mantener" la religiosidad de la población, sino en ayudarla a "madurar" para saber dar razón de su fe y sus formas culturales, en el inevitable diálogo intercultural, principalmente con el occidente secularizado.

Por otra parte, las ciudades presentan un reto cultural de primer orden. Lo señalaba Puebla (429-433) y lo repile Santo Domingo (255-262):

América latina se encuentra hoy en un proceso acelerado de urbanización. La ciudad postindustrial no representa sólo una variante del tradicional hábitat humano, sino que constituye de hecho el paso de la cultura rural a la cultura urbana, sede y motor de la nueva civilización universal (cfr. DP 429). En ella se altera la forma con la cual en un grupo social, en un pueblo, en una nación los hombres cultivan su relación consigo mismos, con los otros, con la naturaleza y con Dios.

En la ciudad, las relaciones con la naturaleza se limitan casi siempre, y por el mismo ser de la ciudad, al proceso de producción de bienes de consumo. La relaciones con las personas se tornan ampliamente funcionales y las relaciones con Dios pasan por una acentuada crisis, porque falta la mediación de la naturaleza tan importante en la religiosidad rural y porque la misma modernidad tiende a cerrar al hombre dentro de la inmanencia del mundo [...]

Nuestras metrópolis latinoamericanas tienen también como característica actual periferias de pobreza y miseria, que casi siempre conslituyen la mayoría de la población, frulo de modelos económicos explotadores y excluyentes. E] mismo campo se urbaniza por la multiplicación de las comunicaciones y transportes.

A su vez, el hombre urbano actual presenta un lipo diverso del hombre rural: confía en la ciencia y en la tecnología; está influido por los grandes medios de comunicación social; es dinámico y proyectado hacia lo nuevo; consumista, audiovisual, anónimo en la masa y desarraigado (255).

Es una lástima que el documento de Santo Domingo, que hace esta descripción tan acertada de los desafíos de la inculturación que representa la cultura urbana hoy, no sea igualmente lúcido a la hora de proponer las líneas pastorales a seguir. Las sugerencias más audaces son la reprogramación de la parroquia urbana y la multiplicación de las pequeñas comunidades (256). Ciertamente, la tarea búsica de la pastoral urbana es la recuperación del sentido de identidad personal y de pertenencia a una comunidad humana y desde ese fundamento, enseñar a descubrir la apertura a la trascendencia, desde las experiencias de la interioridad y de la solidaridad. Otros problemas subordinados son el de la cultura de las áreas marginales de las ciudades, de los jóvenes y de los inmigrantes a la ciudad. No es éste el lugar para analizar todos estos problemas en detalle. 
Concluyo con la observación que hice al principio. El tema de la inculturación como criterio de la acción pastoral no es un tema que surge de la preocpación por las culturas en $\mathrm{s}\rfloor$ mismas, sino del respeto a las personas. El atropello y desprecio a la cultura de una persona lleva implícito el desprecio y atropello a la persona misma, hasta tal punto la comprensión que cada cual tiene de sí se realiza desde la propia cultura. El tema de la inculturación no es, pues exclusivo de los misioneros ad gentes, aunque allí tenga su origen la reflexión sobre la incidencia de la cultura de la evangelización. El tema de la inculturación debe tenerlo en cuenta, por una parte, cada Iglesia particular para estar atenta a la evolución de la cultura en la que está inserta; y, por otra, los agentes de pastoral que ejercen su función en olros pueblos y culturas, para adquirir la flexibilidad y la apertura de mente, necesarios para llevar a cabo un proceso de evangelización inculturada.

Se ha repetido muchas veces que el paradigma teológico de la inculturación es el misterio de la encarnación, pero hay que recordar que el móvil de la encarnacion fue el amor ("tanto amó Dios al mundo", In 3, 16), por lo que el móvil de la inculturación debe ser también el amor. Si no queremos y respetamos a quienes evangelizamos, toda palabra y ciencia sobra. 